\title{
Optimal Use of L1 and L2 in Teaching Chinese to Sri Lankan Students: Approaches and Challenges
}

\author{
*N S Y Dassanayake ${ }^{1}$ \\ ${ }^{1}$ Department of Languages, Faculty of Social Sciences and Languages, Sabaragamuwa University of Sri Lanka, Sri \\ Lanka
}

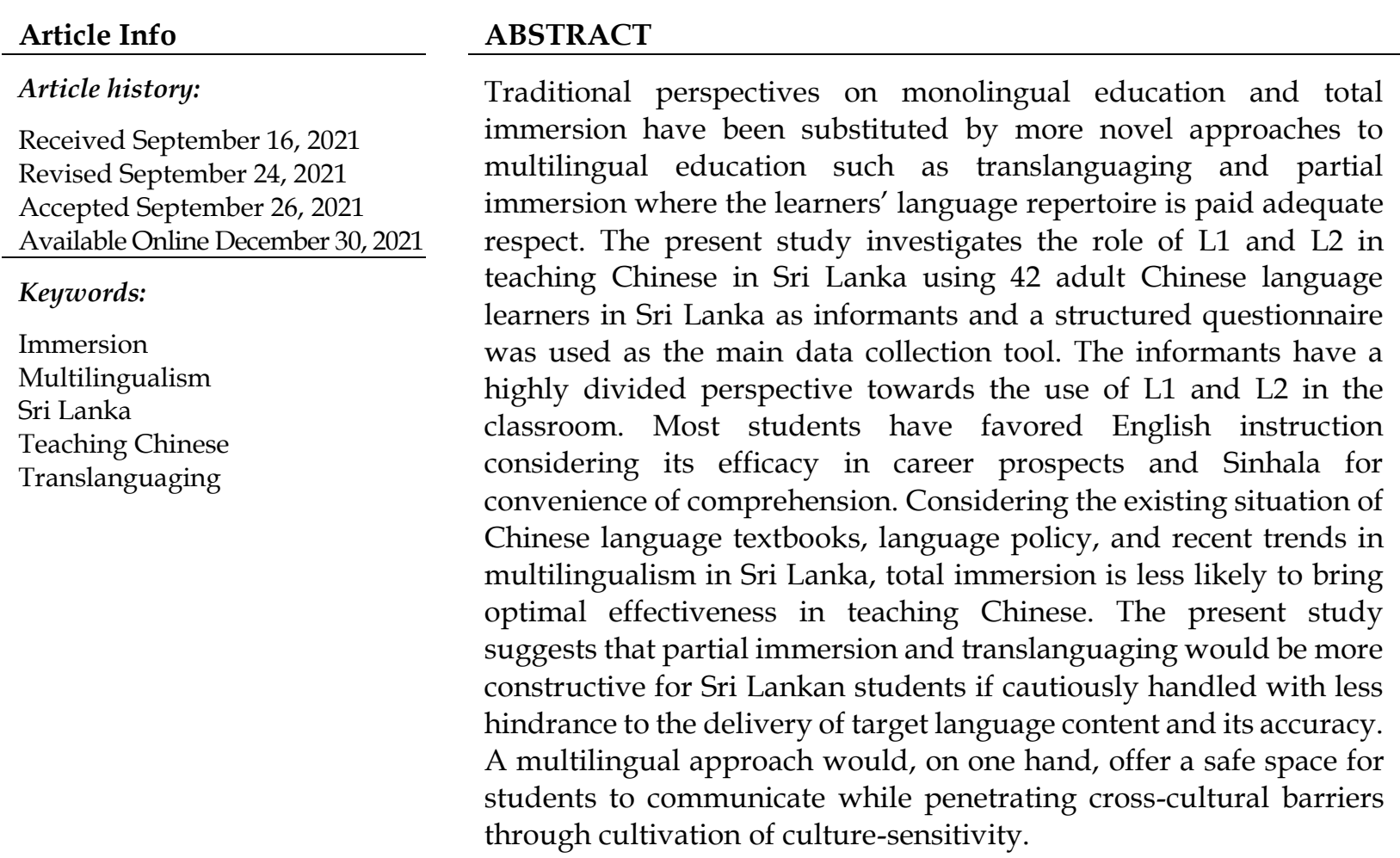

\section{INTRODUCTION}

Exclusive use of mother tongue and L2 in language programs has been an issue of controversy for over decades. According to McMillan \& Turnbull (2009), exclusive use of target language can result in over-reliance on cognates and over simplification of language. Findings of the TARCLINDY ${ }^{1}$ research project (Macaro, 1997) conclude that there are three distinctive personal theories of teachers regarding the first language use. Some teachers tend to believe that second language could only be learnt through that language while some others believed that exclusive use of second language is nearly impossible due to unavailability of the perfect learning conditions in second language classroom. The third belief is that there is considerable value in use of first language in second language learning. (Macaro, 2009) Language transfer and codeswitching in immersion programs are perceived by different researchers in the language field in different perspectives.

Most commonly used instruction languages of Chinese language programs in Sri Lanka are Sinhala and English, the former being the mother tongue of a majority of students and the latter being the second language. Chinese, Sinhala and English belong to three different language

\footnotetext{
${ }^{1}$ TARCLINDY: Abbreviation of target language, collaborative learning and independent learning.
} 
families and there are significant differences between their linguistic systems and features. Although issues of L1 and L2 transfer on Teaching Chinese to Sri Lankan students have been major concerns, they neither have been paid adequate consideration, neither have they been systematically studied. The present study aims to explore the boundaries and efficiency of using L1, L2 and the target language individually and as combinations for instruction in Chinese language programs in Sri Lanka.

\section{RESEARCH METHODS}

The study has utilized multiple approaches to examine the optimal use of each instruction language which includes both qualitative and quantitative methods.

\section{Key Informants}

42 adult Chinese language students in Sri Lanka were randomly selected for the study as primary informants who were from different language and social backgrounds. The diversity of social and linguistic backgrounds of the informants was considered as a positive factor to obtain a wider stance on the multilingual background of Sri Lankan Chinese language students.

\section{Data Collection Tools}

A questionnaire was used as the primary data collection tool and the questionnaire was designed on google forms and all primary data were collected online. The questionnaire consisted of three parts of which the first part was concerned on the multilingual competencies and skills of the students and the second part was dedicated for their opinion on the preferred medium of instruction of each aspect of teaching. The third part consisted of two multiple choice questions which questioned the reasons for the preference of instruction language.

\section{Analysis Methods}

The responses collected through google forms were first transferred into an excel spreadsheet and then each variable and respective data were entered in SPSS. Analysis function was used to calculate percentages, mean values and standard deviation.

A comprehensive survey of literature was conducted parallelly to establish and refine the theoretical framework for the study.

\section{REVIEW OF LITERATURE}

\section{Multilingualism and Second Language Learning}

According to the 2012 special Eurobarometer report on Europeans and their languages, more than $88 \%$ of Europe believe that knowing languages other than their mother tongue is very useful. $67 \%$ of the Europeans believe that English one of the two most important languages for themselves and $98 \%$ of the Europeans believe that mastering foreign languages is useful for the future of their children. Dramatic expansion of cross-cultural contact through digital platforms and immigration in the recent decades have resulted in new language contacts creating multilingual environments all over the world. The interest in multilingualism and multilingual literacy have grown rapidly in last two decades along with significant linguistic, cultural and demographic changes prompted by globalization, transnational population flow, technological advancements and changes in regional political and economic landscapes. (Martin-Jones et al., 2015)

Multilingualism could be defined in terms of language policy, lifestyle, cultural context, politics etc. different approaches. In some cases, multilingualism connects with language policies and language planning. No matter how linguistically diverse a community may be, most countries limit the number of official languages to a small number of languages. What language is used in public services, schools, courts and congress is decided by language policies of the administration. (Maher, 2017) The introduction of English Education in the nineteenth century as a result of colonialism had profound and long-term impacts on Sri Lanka's language policies and 
practice. (Coperehewa, 2011) English still remains largely a colonial aristocratic symbol in Sri Lanka thus limiting its stakeholders mostly to the elite community.

Dominant languages are the greatest threat on multilingualism. According to Casanova \& Jones (2013) the notion of "equity" among languages however true it may be in an absolute sense, is completely false in reality. Among millions of live and extinct languages, there have always been the ones that were more "prestigious" than the other or others. Their proposition is testified by many incidents of dominant languages devouring the less popular ones all over the world. For example, Sinhala language of Sri Lanka consists of a considerable number of luxury loans from English which has resulted in expelling the native forms from daily vernacular. Code switching and code mixing has also resulted in undermining native language vocabulary.

Speaking of language diversity by region, Asia accounts for the highest percentage value in terms of number of languages. 32\% of world's languages are of Asian origin. (Coulmas, 2017) East Asia is one of the most linguistically diverse regions in the world in terms of number of languages as well as their linguistic features. The Asian continent region consists of five major regions, namely South Asia, Southeastern Asia, Central Asia, East Asia and Western Asia. The languages in concern in this study mainly are of South Asian and East Asian origin and primary attention will be drawn towards multilingualism of these regions. According to Gottlieb \& Chen (2013), characterization of East Asian languages including Japanese and Korean have been largely influenced by Chinese. Despite Japan and Korea being a largely monolingual territories for a long time, Japanese and Korean have largely been influenced by Chinese over long cultural contacts.

Chinese language remains the most popular East Asian language and is spoken by one fifth of the world population (Law et al., 2009). Chinese language by itself is diverse with its wide variety of dialects. Chinese consists of seven major dialects, namely Mandarin in the north, Cantonese Yue in south, $\mathrm{Wu}$ in Shanghai region, Xiang, Gan Kejia and Min. (Taylor \& Taylor, 1995) Chinese is widely contributed to creating multilingual environments in East Asian and South East Asian countries making a wide impact on the multilingualism and language policies of Singapore, Vietnam, Philippines, Indonesia etc. countries. Many of these countries have Chinese language immersion programs in Chinese schools specially meant to cater for overseas Chinese children who the Chinese refer to as Huaren 2. Pasaribu \& Suprapto (2020) discusses the language issues faced by foreign students in Taiwan and claim that although there is English instruction in the Chinese class, there is always the need to resort to Chinese outside class which is not easy due to the language competency barriers.

The quadrilingual teaching model in Singapore in one hand is implicit of Singapore's diverse multilingualism and on the other hand its pedagogical implications could be of much use for developing multilingual instruction models. Although the language requirements at individual level remain bilingual in Singapore, it would be more accurate to describe the language policy of Singapore as a quadrilingual model because all four official languages are treated as equal players in the national agenda. (Silver \& Bokhorst-Heng, 2016) Equality among languages is a core principle of Singapore's language policy. According to Rappa \& Wee (2006) the widespread use of English is less problematic since there are no privileged languages in Singapore and all languages are treated as equally important.

China has largely been a monolingual territory at least until the reform and opening up policy of Deng Xiaoping in 1978. However, this does not necessarily mean that Chinese language has not had contacts and influences from other languages. Efforts towards multilingualism in China has more been multi-dialectical rather than multilingual with several different mutually unintelligible dialects spread all over China. Cantonese one of the most distinctive and widely spoken dialects in China has had a wide influence within and outside China. However, the language policies in China after the Reform and Opening Up movement in 1978 were more

\footnotetext{
${ }^{2}$ Huaren 华人: The term used by Chinese people to refer to people of Chinese origin living in overseas territories. There are special benchmarks prepared for measuring the Chinese language skills of this overseas Chinese people which is different from Teaching Chinese as a Foreign Language (TCFL).
} 
directed towards promotion and standardization of Putonghua, the major dialect. (Liang, 2014) Along with these reformations, the requirement for equipping the Chinese community with international languages to cope with the globalized trade became imperative. Language policy reformations in China shifted its focus from regional dialects to international languages. Out of all the dramatic transformations occurred in China in the last few decades, one of the significant changes was the embracing and promotion of English both at school level and after school level. (Pan, 2014).

The second most important topic related to the present research is multilingualism in South Asia. Most South Asian languages belong to the Indo-Aryan or Dravidian language families and few other languages of Tibeto-Burman and Munda families. As Kachru et al. (2008) suggests, diffusion, mutual contact and convergence are essential characteristics of South Asian languages in their historical and functional contexts. Colonial occupation of Portuguese, Dutch and English was a decisive factor on characterization of Multilingualism in South Asian context. As Kudchedkar (2002) narrates although English ruled nearly two hundred years their language is ruling much longer than that and it doesn't look like leaving the territory. The situation is much similar in most South Asian countries including Bangladesh, Pakistan and Sri Lanka. During the British colonial era, only those who could afford to go to English taught schools had the privilege of learning English and it prevented the children of lower social class from receiving comprehensive English education. (Karunaratne, 2009) However, English has already secured its prestigious position in the India, Sri Lanka etc. South Asian countries that English is no more considered as a qualification but as a prerequisite for employment.

It is important to pay specific attention to the language situation of the country in question in this research. The Indian subcontinent had been multilinguistic from thousands of years ago and its influence has been high on the language situation in Sri Lanka. The first Indian settlers of Sri Lanka lead by Vijaya were of Western Indian origin and preferably spoke a dialect of that region. Soon after the first settlements trade and commerce were established with Eastern parts of India and new immigrants preferably spoke an Eastern Indian dialect. (Geiger, 1995) Along with the introduction of Buddhism to Sri Lanka in 1st Century, Sanskrit and Pali became popular in Sri Lanka. Dravidian languages, mainly Tamil have also been an important language largely spoken in the Northern and Eastern parts of Sri Lanka. In addition to Colonial English, many other foreign languages became popular in Sri Lanka including French, German etc. IndoEuropean languages and Chinese, Japanese, Korean etc. East Asian languages. Hindi is the most widely taught South Asian foreign language in Sri Lanka.

\section{Cross-linguistic Transfer and Foreign Language learning}

According to Odlin and Yu (2016), even when only two languages are in contact, cross-linguistic influence may occur in different ways. Typically, language transfer mostly involves divergences between source and target language which result in negative transfer. Cross-linguistic influence is inevitable in a multilinguistic environment and it is a decisive factor in the pedagogy of second language and foreign language. Existing approaches to interlanguage transfer are highly restricted, which mostly involve interaction between two languages. The presence of more than two linguistic systems in the speakers' mind is essential for interlanguage transfer to occur. (Angelis \& Selinker, 2001) The traditional hypothesis that transfer only occurs from mother tongue to second and third languages has been overshadowed by novel approaches to transfer which have validated that transfer is a two-way process and could occur between L2 and L3 too.

Language transfer could be perceived from its impact on the recipient language as positive and negative transfer. Wang \& Garigliano (1992) define positive transfer as transfer which makes learning easier as in Chinese and English syntax which can facilitate acquisition of Chinese grammar. Negative transfer is defined as transfer which leads to 'error' or 'inappropriate form' in target language acquisition. According to Ellis (1994), the degree of difficulty in L2 learning is dependent on the extent of differences between native language and target language patterns. Learning is made easy in cases where the two are identical through positive transfer but negative 
transfer is likely to occur in cases where there are differences between the native language patterns and the target language patterns.

Influence of L1 or the mother tongue has been a key topic of discussion in second and foreign language learning. Vainikka \& Young-Scholten (2006) suggest that the extent to which L1 influences the acquisition of syntactic structures of $\mathrm{L} 2$ throughout development is an unresolved issue. However, the influence of mother tongue cannot be considered the only influential factor on foreign language learning. According to Angelovska \& Hahn (2012) although first language has been considered as the main source of transfer on acquisition of other languages, it cannot be concluded that the first language is necessarily the major source or an inevitable source of transfer. Mother tongue influence has to be more carefully analyzed in contexts as South Asia where English as a second language is highly influential in foreign language learning.

The use of mother tongue in second and foreign language learning has been a controversial topic throughout the history of second and foreign language research. Some scholars perceive the use of mother tongue as a destructive influence in second and foreign language acquisition while there are many others who perceive it as an asset. According to Ali et al., (2015) despite the prejudice against the use of L1 for teaching foreign languages, both empirical and theoretical findings demonstrate that L1 could be a "precious source" in assisting teachers to improve target language skills. Krashen (1981) has discussed first language influence from different perspectives and claim that first language influence is strongest in environments where "acquisition is poor" and its influence is weaker in bound morphology.

\section{RESULTS AND DISCUSSION \\ Survey Results}

The primary informants of the present study were a group of 42 Chinese language students of diverse language levels. Diversity of linguistic background was considered as a positive factor since this would provide a clearer picture of the preferred instruction language. $71.4 \%$ of the informants were in the age group between 20-29, 21.4\% were under age 19 and the rest were in the age group between 30-39. The first section of the questionnaire was aimed at drawing information on the linguistic background of the students. To the question on what languages the informants were speaking, $100 \%$ of the students have answered that they were able to speak Sinhala and 72.4\% students have answered that they are able to speak in English. Sri Lanka's third language Tamil was spoken only by $6.9 \%$ students and Korean, Japanese and Hindi were spoken by only one student each.

Table 1. Language proficiency levels of informants and most convenient language

\begin{tabular}{llccc}
\hline & Proficiency Level & \multicolumn{3}{c}{ Language } \\
\cline { 3 - 5 } & & Sinhala & English & Chinese \\
\hline Language proficiency levels & Highly Proficient & $90.47 \%$ & $21.42 \%$ & $4.76 \%$ \\
& Good & $9.52 \%$ & $52.3 \%$ & $33.33 \%$ \\
& Working Knowledge & $0 \%$ & $23.8 \%$ & $52.38 \%$ \\
& Poor & $0 \%$ & $0 \%$ & $2.38 \%$ \\
& Very Poor & $0 \%$ & $0 \%$ & $0 \%$ \\
& $\mathrm{n}$ & 42 & 42 & 42 \\
\hline Most convenient language & mean & 1.0952 & 2.0238 & 2.5952 \\
\hline
\end{tabular}


Table 2. Language skills of informants

\begin{tabular}{lcccccccccc}
\hline \multirow{2}{*}{ Language Skill } & \multirow{2}{*}{$\mathrm{n}$} & \multicolumn{4}{c}{ Sinhala } & \multicolumn{4}{c}{ English } & \multicolumn{3}{c}{ Chinese } \\
\cline { 3 - 12 } & & $\%$ & mean & std.dev & $\%$ & mean & std.dev & $\%$ & mean & std.dev \\
\hline Understand & 42 & 100 & 1.00 & 0.00 & 90.47 & 0.90 & 0.29 & 73.80 & 0.74 & 0.44 \\
Speak & 42 & 78.57 & 0.78 & 0.41 & 83.33 & 0.83 & 0.37 & 59.52 & 0.60 & 0.49 \\
Read & 42 & 78.57 & 0.78 & 0.41 & 78.57 & 0.78 & 0.41 & 73.80 & 0.74 & 0.44 \\
Write & 42 & 61.9 & 0.61 & 0.49 & 61.90 & 0.61 & 0.49 & 57.14 & 0.57 & 0.50 \\
\hline
\end{tabular}

Table 1 and Table 2 give a clear picture of the language competencies and language skills of the informants. Most students claim to be highly proficient in their mother tongue and nearly $50 \%$ of the students claim to possess working knowledge in English. Only $4.76 \%$ of the informants have claimed that they are highly proficient in Chinese language and a majority $(85.68 \%)$ have claimed that they possess either good or working knowledge in Chinese. With regard to the language skills of the students, reading and comprehension skills of the students are relatively higher than speaking and writing. The overall mean value of reading and comprehension skills of the students in all three languages is higher ([Comprehension 1.00+0.90+0.74] +[Reading $0.78+0.78+0.74] / 6=0.82$ ) in contrast to that of speaking and writing ([Speaking $0.78+0.83+0.60]+[$ Writing $0.61+0.61+0.57] / 6=0.66)$. Except for $16.66 \%$ students who have selected English as the most convenient language to communicate all others have selected Sinhala as the most convenient language to communicate.

Table 3. Medium of instruction: existing situation and preference

\begin{tabular}{lll}
\hline Medium of instruction & $\begin{array}{l}\text { Preferred language of } \\
\text { instruction }\end{array}$ & $\begin{array}{l}\text { Prevailing language } \\
\text { instruction in the classroom }\end{array}$ \\
\hline Only Chinese instruction & $2.4 \%$ & $2.4 \%$ \\
Chinese Sinhala bilingual instruction & $45.2 \%$ & $47.6 \%$ \\
Chinese English bilingual instruction & $45.2 \%$ & $47.6 \%$ \\
All explanations in Sinhala & $4.8 \%$ & $2.4 \%$ \\
All explanations in English & $2.4 \%$ & $0 \%$ \\
n & 42 & 42 \\
Mean & 2.59 & 2.50 \\
Std.Dev & 0.73 & 0.59 \\
\hline
\end{tabular}

From the table 3 it is evident that the preferred medium of instruction is quite debatable among the students. Except for 4 students all other students have resorted for Chinese-Sinhala bilingual instruction or Chinese-English bilingual instruction. The prevailing situation with regard to the medium of instruction in the Sri Lankan Chinese language classroom has only catered the expectations of only some students. Specifically referring to the informants of this study, only nearly half of them have been satisfied about the medium of instruction in the Chinese language classroom while the other half preferred another medium of instruction.

Table 4. Medium of instruction: existing situation and preference

\begin{tabular}{lccc}
\hline Response & $\%$ & Mean & Std. Dev \\
\hline I want to improve my English along with Chinese & 61 & .59 & .49 \\
I think English translations will be more useful in future career & 68.3 & .66 & .47 \\
English examples are easier to understand & 31.7 & .30 & .46 \\
I don't want English instructions in the classroom & 0 & .00 & .00 \\
English explanations are more suitable for Chinese words & 24.4 & .23 & .43 \\
\hline
\end{tabular}

To the question in which areas do the students need mother tongue (Sinhala) explanations in the Chinese classroom $47.6 \%$ of the students have answered that they need Sinhala explanations for grammar and $31 \%$ of the students have responded that they need Sinhala instructions for translation methods. The question was limited to single choice thus limiting the responses to the most preferred aspect. 9.5\% informants have chosen that they need Sinhala instructions for new word meanings and $7.1 \%$ have prioritized text. 
According to table 3 the strongest reason behind the preference of English language instruction is students' perception of English as a necessary aptitude for future career prospects. 61.3\% informants have responded that they prefer English instruction since it would improve their English alongside Chinese. 31.7\% students have claimed that it is easier to comprehend English examples and 24.4\% informants have claimed that English examples are more suitable for Chinese words. None of the informants have responded that they do not need English language instruction in the classroom which implies that all the informants are in favour of at least some incorporation of English language in the Chinese language classroom.

Table 5. Students' opinion on sinhala medium instruction

\begin{tabular}{lccc}
\hline Response & $\%$ & Mean & Std. Dev \\
\hline I can easily understand Sinhala meanings & 92.7 & .90 & .29 \\
I find English and Chinese instructions difficult to understand & 12.2 & .11 & .32 \\
I want to improve my Sinhala language & 0 & .00 & .00 \\
I don't want Sinhala instructions in the class & 7.3 & .07 & .26 \\
\hline
\end{tabular}

Responses on the use of Sinhala language in the classroom show that most students prefer Sinhala instruction for ease of comprehension. However, unlike on English instruction where none of the students are against it, $7.3 \%$ students have responded that they do not need Sinhala medium instruction in the Chinese language class. $12.2 \%$ students have responded that they prefer Sinhala instructions because they find English instructions difficult to comprehend.

\section{Discussion}

Few important inferences could be drawn from the data analysis. A majority of students have either preferred bilingual or trilingual instruction in the classroom where their mother tongue Sinhala or English is expected to involve in instructions, descriptions and clarifications of linguistic elements of the target language. In a broader sense, the informants seem to have a positive attitude towards cross-linguistic transfer from their mother tongue and second language. Nevertheless, the informants' preference of instruction language appears to be highly controversial since L1 and L2 both are perceived as the preferred language of instruction by nearly $50 \%$ of the students each. This has to be analysed in relation to the multilinguistic situation in Sri Lanka. As emphasized in a previous section, Sinhala as the mother tongue of a majority of population and English as official second language of the country at large are the most spoken languages in Sri Lanka.

The informants' preference of Sinhala as medium of instruction is justifiable since its natural of any foreign language learner to seek for help from their mother tongue for convenience but the reasons behind students' preference of English as medium of instruction is worth investigating further. According to the English Impact 2018 report by the British Council and Ministry of Education in Sri Lanka, a majority of the sample students' (58.2\%) are in level A1 of CEFR ${ }^{3}$ and second largest group (29.2\%) are in level A2 of CEFR. The report further demonstrates that the receptive skills are much higher than productive skills of Sri Lankan students. 39.6\% students are at level B1 of CEFR in reading while $56.1 \%$ are at A2 in reading. (Shepherd \& Ainsworth, 2018) Although these are relatively low numbers and as Liyanage (2019) claims, the bilingual education in Sri Lanka remains an 'unrealized policy objective', the demand and motivation for learning English are still growing rapidly. According to the analysis of the responses in the present study, $668 \%$ of the informants have responded that they believe English translations to be useful for their future career prospects while $61 \%$ of the students have responded that they need English language instruction in the Chinese classroom because they need to improve their English language alongside Chinese.

A considerable number of Indic loanwords were borrowed into Chinese along with the sutra translations from Sanskrit, Gandhari, Magadhan etc. Indic languages. According to Yu (2008)

${ }^{3}$ CEFR - Common European Framework of Reference for Languages 
Buddhist sutra translations facilitated the emergence of 佛教混合汉语 fójiào hùnhé hànyǔ "Buddhist Hybrid Chinese". The aforementioned "Buddhist Hybrid Chinese" consists of a large number of transliterations which are phonologically similar to their original words in Indo-Aryan languages. Similarly, Sinhala also consists of a substantial number of loanwords from Indic languages most of which are of Buddhist origin. These two parallel processes have resulted in phonological similarities between Buddhist loanwords in Chinese and Sinhala since both languages have borrowed from the similar source languages. How this relates to teaching Chinese in Sri Lanka is that these phonological and semantic similarities could be utilized in teaching Chinese phonetics and word formation strategies. Otherwise stated, Indic loanwords in Chinese and their Sinhala counterparts could be utilized in positive transfer to assist language acquisition. Therefore, although mother tongue is traditionally viewed as a negative influence on second and foreign language acquisition, its positive impact could not be totally neglected.

Three key questions arise in choosing between the most effective method of instruction for Chinese language classroom in Sri Lanka.

i. Is total immersion going to be an option?

ii. Would students be more benefitted by a bilingual model or a trilingual model?

iii. To which extent does mother tongue and English could be utilized in the classroom?

Although immersion is a widely used method of teaching, and proven effective in many contexts, it is a question whether immersion may prove similarly effective in every context. Immersion programs may vary depending on the proportion of instructional time spent in the target language and the age of students in which immersion instruction begins. There are total and partial immersion programs which use different proportions of target and native languages. (Siegel et al., 2010) In a context as in Sri Lanka, where transfer from L2 is as influential as transfer from L1, total immersion would be less effective. Majority of TCFL textbooks used in Sri Lanka are designed using English as the instruction language which makes the involvement of English an inevitable factor. Although this is a matter of preparing context-oriented textbooks and study material using native language for TCFL in Sri Lanka, using English at least to some extent is unavoidable in order to grapple with the present situation. Secondly, one of the key issues in teaching forms and structures of Chinese language is finding Sinhala equivalents for technical terms. Counterparts for Chinese grammatical terms such as 'predicate', 'complement', 'aspect particle' are either unavailable in Sinhala or even if available students are hardly familiar with them compared with their English equivalents.

Although English is considered as L2 in the Sri Lankan context and language policy and planning differs much from Singapore, English language situation in Sri Lanka is much similar to that of in Singapore. As stated by $(\mathrm{Goh}, 2020)$ the dominance of English language extends well beyond education in Singapore to almost every formal domain including politics, law, business, technology and public administration. Despite language policy and planning efforts in Sri Lanka still remain much less effective in ameliorating English literacy at large, the role of English extends well beyond functioning as a lingua franca. Analysis of key informants' responses prove that preference for English language instruction is much higher than Sinhala and are mostly aimed at career development. The reasons for preference of Sinhala language appear to be aimed at convenience in learning. Both these factors have to be carefully analysed when deciding on the medium of instruction and the proportion and extent of using L1 and L2 in the classroom. When we accumulate the data from relevant literature and the informants, it could be concluded that total immersion is less likely to be an option for teaching Chinese in Sri Lanka. Ahaddin et al. (2020) have investigated into the possibility of using peer instruction in classroom and claim that peer instruction has a high impact on enhancing the critical thinking skills of students. This could be a viable solution for language students since peer instruction would preferably drive away any linguistic barriers which occur in teacher instruction and provide a safe space for students to communicate in languages they are familiar with.

Translanguaging has been a topic of discussion which has emerged as an extension of bilingual programs. Translanguaging offers the learner a wider space to use the languages they 
are competent with beyond the borders of bilingualism. According to García \& Kleyn (2016), in translanguaging all the language features of students' repertoires are acknowledged, valued and deployed in learning. Translanguaging could also be considered as a workable solution for teaching Chinese in Sri Lanka where L1 and L2 are considered as equally important as the new language. To the question how translanguaging differs from code-switching and code-mixing Lin (2020) concludes, despite translanguaging at surface level sounds similar to code-switching and code-mixing, the term refers to a more 'dynamic' and 'fluid' view of language. According to Wang (2018) translanguaging is a phenomenon that respects superdiverse multilingual social conditions and accepts all resourceful semiotic and linguistic inventions of teachers and students.

A translanguaging model could make L1, L2 and the target language inclusive in the classroom which will benefit bilingual and multilingual learners by providing them a safe space to communicate freely in the language classroom. The core issue, however, would be how translanguaging could be integrated into Chinese language classroom of Sri Lanka. Age, linguistic diversity, bilingual/multilingual competency levels, class strength etc. factors have to be considered before deciding on medium(s) of instruction. For example, in a classroom with a majority of low English competency adult learners, translanguaging would be impractical and would have to resort to a bilingual model. At the same time, the amount of contact hours allocated for a programme also become a crucial factor since translanguaging would be more time consuming which may hinder the delivery of adequate target language content.

While translanguaging could be an option for students who learn Chinese from early ages, a different approach will have to be taken for adult learners who follow Chinese for professional and academic purposes. Therefore, the extent of using L1 and L2 have to be considered for adult learners who learn Chinese for short courses and for undergraduate programmes. A majority of the informants who have participated in the present study are adult learners between the ages of 20-39 except for $14 \%$ of the informants who are under age 19. According to Carder (2007), mothertongue proficiency is a crucial factor behind successful mastery of L2. As previously emphasized, although mother-tongue immersion has been a controversial issue for over decades, its positive impacts on L2 and foreign language acquisition cannot be totally neglected. A partial immersion approach using either L1 or L2 or both depending on the context would be more appropriate for these two types of programmes. However, educators have to ensure that L1 and L2 do not act as negative transfer agents in classroom hindering the accuracy of target language acquisition.

In translanguaging and partial immersion the teacher has to have a considerable competency, fluency and accuracy in all the languages used in the classroom including a fair knowledge of the language systems of the languages. Chinese being a tonal language of Sino-Tibetan language family has to be handled with extra sensitivity to its culture and terminology. Bernaus (2007) claim that Language awareness can never be dissociated from cultural awareness and language learners should have multidimensional cultural awareness in multicultural, pluricultural and intercultural aspects while Kim (2020) claim that an adequate account of culture is essential to create language pedagogy that supports more effective intercultural communication. Cultureloaded words are a key element of culture-sensitive content of a language. According to Yuewu \& Qin (2015), culture-loaded words are the words, idioms and expressions which incorporate specific cultural meanings. Familiarization with this content is of paramount importance for teachers in order to incorporate culture-sensitivity into a multilingual classroom.

\section{CONCLUSION}

Although teaching Chinese in Sri Lanka has drawn much attention during the past few years with the growing demand for Chinese competency in the job market, little has been studied on the role of L1 and L2 in the Chinese language classroom which has led to inconsistency of the medium of instruction. The results of the present study also reveal that the students' perspective on the medium of instruction is highly divided. Despite the traditional negative stance on the use of L1 and L2 in the teaching foreign languages, there is much theoretical and empirical evidence to support the fact that they could be constructively utilized in teaching foreign languages. While 
the present study suggests that total immersion would not bring much success into the Chinese language classroom in Sri Lanka, the extents and proportions of using L1 and/or L2 in the classroom is to be decided after careful consideration of the age, L1 and L2 competency, time duration etc. factors. The present study has only analyzed medium of instruction from a multilingual perspective and further research on this could be conducted from a plurilingual perspective.

\section{ACKNOWLEDGEMENTS}

I express my sincere gratitude to the key informants of the study for their sincerity in providing their valuable data for this study.

\section{REFERENCES}

Ahaddin, M. A., Jatmiko, B., Supardi, Z.A.I. The improvement of critical thinking skills of primary school students through guided inquiry learning models with integrated peer instructions. Studies in Learning and Teaching, 1(2). https://doi.org/10.46627/silet.v1i2.39

Ali, S., Namaghi, O., Norouzi , S. (2015). First language use in teaching a foreign Language: Theoretical perspectives and empirical findings. US-China Foreign Language, 13(9). https://doi.org/10.17265/1539-8080/2015.09.001

Angelis, G. D., \& Selinker, L. (2001). Interlanguage transfer and competing linguistic systems in the multilingual mind. In J. Cenoz, B. Hufeisen, \& U. Jessner (Eds.), Cross-Linguistic Influence in Third Language Acquisition, 42-58. https:// doi.org/10.21832/9781853595509-004

Angelovska, T., Hahn, A. (2012). Written L3 (English): Transfer phenomena of L2 (German) lexical and syntactic properties. In D. Gabrys-Barker (Eds.), Second Language Learning and Teaching, 23-40. https://doi.org/10.1007/978-3-642-29557-7_2

Carder, M. (2007). Bilingualism in international schools: A model for enriching language education. Multilingual Matters.

Casanova, P., \& Jones, M. (2013). What is a dominant language? Giacomo Leopardi: Theoretician of linguistic inequality. New Literary History, 44(3), 379-399. https://doi:10.1353/nlh.2013.0028

Coperehewa, S. (2011). Colonialism and problems of language policy: Formulation of a colonial language policy in Sri Lanka. Sri Lanka Journal of Advanced Social Studies, 1(1). https://doi.org/10.4038/sljass.v1i1.3814

Coulmas, F. (2017). An introduction to multilingualism language in a changing world. Oxford University Press.

Ellis, R. (1994). The study of second language acquisition. Oxford University Press.

European Commission. (2012). Special Eurobarometer 386: Europeans and their Languages.

García O., \& Kleyn, T. (2016). Translanguaging with multilingual students: Learning from classroom moments. Routledge.

Geiger, W. (1995). A grammar of the Sinhalese language. Asian Educational Services.

Goh, Y.-S. (2020). Teaching Chinese as an international language: A Singapore perspective. Cambridge University Press.

Gottlieb, N., \& Chen, P. (2013). Language planning and language policy: East Asian perspectives. Routledge.

Kachru, B. B., Kachru, Y., \& Sridhar, S. N. (2008). Introduction. In Language in South Asia. Introduction. Cambridge University Press.

Karunaratne, I. M. (2009). Teaching of English: A sociological study. APH Pub. Corp.

Kim, D. (2020). Learning language, learning culture: Teaching language to the whole student. ECNU Review of Education, 3(3), 519-541. https:// doi.org/10.1177/2096531120936693

Krashen, S. (1981). Second language acquisition and second language learning. Pergamon.

Kudchedkar, S. (2002). Readings in English language teaching in India. Orient Blackswan.

Law, S.-P., Weekes, B., \& Wong, A. M.-Y. (2009). Language disorders in speakers of Chinese. Multilingual Matters. 
Liang, S. (2014). Language attitudes and identities in multilingual China: A Linguistic ethnography. Springer.

Lin, A. M. Y. (2020). Introduction: Translanguaging and translanguaging pedagogies. In V. Vaish (Eds.), Translanguaging in multilingual English classrooms: An Asian perspective and contexts ( $\mathrm{p}$. 3). Springer Nature.

Liyanage, I. (2019). Language education policy in Sri Lanka. In A. Kirkpatrick \& A. L. Liddicoat (Eds.), The Routledge international handbook of language education policy in Asia (pp. 399-413). Routledge.

Macaro, E. (1997). Target language, collaborative learning and autonomy. Multilingual Matters.

Macaro, E. (2009). Teacher use of codeswitching in the second language classroom: Exploring 'optimal' use. In M. Turnbull \& J. Dailey-O'Cain (Eds.), First language use in second and foreign language learning, 35-49. https:// doi.org/10.21832/9781847691972-005

Maher, J. C. (2017). Multilingualism: A very short introduction. Oxford University Press.

Martin-Jones, M., Blackledge, A., \& Creese, A. (2015). The Routledge handbook of multilingualism. Routledge.

McMillan, B., Turnbull, M. (2009). Teachers' use of the first language in French immersion: Revisiting a core principle. In M. Turnbull \& J. Dailey-O'Cain (Eds.), First language use in second and foreign language learning, 15-34. https:// doi.org/10.21832/9781847691972-004

Mercè, B. (2007). Plurilingual and pluricultural awareness in language teacher education: A training kit. Council of Europe.

Pan, L. (2014). English as a global language in China: Deconstructing the ideological discourses of English in language education. Springer.

Pasaribu, M. A., \& Suprapto, N. (2020). Experiences in Chinese class for Indonesian elementary students in Taiwan. Studies in Learning and Teaching, 1(1). https://doi.org/10.46627/silet.v1i1.19

Rappa, A. L., \& Wee, L. (2006). Language policy and modernity in Southeast Asia Malaysia, the Philippines, Singapore, and Thailand. Springer Science Business Media, Inc.

Shepherd, E., Ainsworth, V. (2018). English impact: An evaluation of English language capability Sri Lanka. British Council.

Siegel, L., Pei, M., Qiang, H., Zhao, W., \& Zhao, L. (2010). Teaching English to Chinese-speaking children. In E. Knell (Ed.), Revisiting the Chinese learner. Springer.

Silver, R. E., \& Bokhorst-Heng, W. D. (2016). Overarching themes, bilingual dreams and multilingual landscapes: Quadrilingual education in Singapore. In R. E. Silver \& W. D. Bokhorst-Heng (Eds.), Quadrilingual education in Singapore pedagogical innovation in language education. Springer Singapore.

Taylor, I., \& Taylor, M. M. (1995). Writing and literacy in Chinese, Korean and Japanese. Benjamins.

Vainikka, A., \& Young-Scholten, M. (2006). The roots of syntax and how they grow: The roots of syntax and how they grow: Organic grammar, the basic variety and processability theory. In B. D. Schwartz, \& S. Unsworth (Eds.), Paths of development in L1 and L2 acquisition: In honor of Bonnie D. Schwartz. J. Benjamins Pub. Co.

Wang, D. (2018). Multilingualism and translanguaging in Chinese language classrooms. Palgrave Macmillan.

Wang Y., \& Garigliano R. (1992) An intelligent language tutoring system for handling errors caused by transfer. Intelligent Tutoring Systems (ITS) 1992, Montréal, Canada, 395-404. https://doi.org/10.1007/3-540-55606-0_47

Yu, L., \& Odlin, T. (2016). New perspectives on transfer in second language learning. Multilingual Matters.

Yu, W. (2008). The influence of Buddhist words on Chinese [佛教词语对汉语的影响]. Journal of Baicheng Normal College, 22(1), 68.

Yuewu, L., \& Qin, Y. (2015). An investigation into the culture-loaded words learning by English majors in a vocational college in China. English Language Teaching, 8(8). 
Optimal Use of L1 and L2 in Teaching Chinese to Sri Lankan Students: Approaches and Challenges https://doi.org/10.46627/silet.v2i3.78

Author (s):

*Noel Sampath Yasasri Dassanayake (Corresponding Author)

Department of Languages, Faculty of Social Sciences and Languages,

Sabaragamuwa University of Sri Lanka, Sri Lanka,

4/5, Amuthagoda Factory Watta, Hidellana, Ratnapura, Sri Lanka

Email: noel@ssl.sab.ac.lk 